\title{
HACIA LA COMPASIÓN POR MEDIO DEL LENGUAJE SIMBÓLICO
}

Ana Barberena*

RESUMEN: La falta de estructuras, leyes y normas obligan a enfrentar el desencanto y recrear significados. El hombre será lo que haga de sí mismo y el lenguaje simbólico es su universo de posibilidad: pensar desde la alteridad, concebir al símbolo como compasión que invita a intentar comprender.

$$
\text { rose }
$$

ABSTRACT: The lack of structures, laws, and norms lead to facing disillusionment and searching for reformulations of meaning. Man will be what he makes of himself and symbolic language is his realm of possibility: thinking from another perspective and perceiving the symbol as compassion, inviting us to understand.

PALABRAS CLAVE: símbolo, compasión, alteridad, hermenéutica, epifanía. KEYWORDS: symbol, compassion, alterity, hermeneutics, epiphany.

RECEPCIÓN: 10 de agosto de 2008. APROBACIÓN: 23 de febrero de 2009.

* Escritora. 
CITAM Derechos Reservados.

La reproducción total o parcial de este artículo se podrá hacer si el ITAM otorga la autorización previamente por escrito. 


\section{HACIA LA COMPASIÓN POR MEDIO DEL LENGUAJE SIMBÓLICO}

Es hora de crear nuevos símbolos. Es hora, también, de largos silencios, de interiorización, de prudencia. Estar atento y formular la pregunta.

Chantal Maillard

\section{Introducción}

$\mathrm{E}_{1 \text { escritor Amos Oz, al momento de }}$ recibir el Premio Goethe de Literatura en agosto del 2005, pronunció un discurso sumamente evocador sobre el mal. El famoso escritor hablaba de su niñez, de su raigambre judía y de su aversión a los alemanes. Conforme pasó el tiempo, contó que tuvo la oportunidad de conocer a algunos autores de origen germano, así como a colegas que le compartieron su cultura, y que en sus propias palabras "le seducían para que se imaginase en su lugar". ${ }^{1}$

Oz rescata la literatura y le confiere poderes curativos. Vínculo entre los hombres, la literatura es el medio donde la imaginación recrea y se "emparenta" con otros mundos, pareciera incluso, que a pesar de uno mismo. El final del texto es contundente: "imaginar al otro no es una mera herramienta estética, es además un imperativo moral fundamental. Y sobre todo, imaginar al otro, es un placer humano profundo y muy sutil". ${ }^{2}$

Quisiera retomar esta intuición que me ha servido de inspiración, el cual parte de dos premisas fundamentales: el mundo globalizado ha puesto sobre la mesa una nueva forma de convivencia. Hace sólo cincuenta años, la mayoría de la gente nacía, vivía y moría en el

${ }^{1}$ Amos Oz. "El mal tiene un olor inconfundible," en El País, Babelia (1-10-05), p. 24.

${ }^{2}$ Ibidem. 
mismo lugar; los desplazamientos no eran muy comunes y la población en general no vivía intensos movimientos migratorios, a excepción de conflictos específicos y en su mayoría militares como son la Guerra civil española, la Guerra de los Balcanes, por mencionar algunos. Hoy en día, el mundo tiene una condición de mayor movilidad, hay una enorme circulación de personas en el ámbito mundial cuyo desplazamiento obedece a la necesidad de buscar una mejor forma de vida. La migración, según datos de la ONU, señala que el número de migrantes internacionales aumentó de 75 millones en 1965 a 120 millones en 1990. Las ciudades están tomando una fisonomía que en ocasiones nos impide reconocer la raza original, por lo menos en la forma, e incluso podríamos decir que se está gestando un mundo interracial.

El espacio compartido, la convivencia cercana entre miembros de distintas razas en una misma ciudad, ha provocado que el hombre, hoy quizá más que nunca, se tope con el otro: espejo en el cual no se quiere mirar y en el cual no se reconoce, el hombre es portador de su propia exclusión, de su relegación y su confinamiento. No nos entendemos y no queremos entendernos. Quizá lo que ocurre es que no sabemos leernos.

De esta idea, quisiera desprender la primera preocupación que figura como móvil de la presente investigación: ¿qué es aquello que nos impide comunicarnos?, ¿cómo podemos acercarnos al otro?, ¿no será que hemos olvidado la primera forma, la más original, de comunicación? El hombre primitivo se valió del mito para nombrar su mundo, y fue por medio del símbolo que el pensamiento mítico se compartió. La forma como entenderemos el mito será más allá de un mero relato: hablaremos del mito desde su originalidad y su unidad; como forma autónoma de pensamiento y de vida. El mito tiene la cualidad de abstraer una totalidad que, aún y cuando es percibida por el sujeto, es muestra de lo universal, lo incluyente, lo común, pues nuestro entorno le es común a todos los hombres. En palabras de Vicente Vide los mitos: "son lenguajes paradigmáticos, y arquetípicos, que vinculan experiencias fundantes y fundamentales de la vida al modo de Axis Mundi, ejes básicos de la existencia". ${ }^{3}$

${ }^{3}$ Vicente Vide, "Mito", en Claves de Hermenéutica, 2005, Bilbao, Universidad de Deusto, p. 402. 
Si hablar de mito nos remite al símbolo, será imperativo desprender las siguientes preguntas: ¿qué es un símbolo?, ¿cómo se articula el símbolo? Y como preguntas derivadas de estos primeros cuestionamientos, podríamos abordar la manera cómo el símbolo pervive gracias al hombre: ¿qué relación tiene con la razón?, ¿el lenguaje simbólico es en sus manifestaciones la esperanza de una forma de comunicación universal?

Adentrémonos pues, a explorar el símbolo desde la experiencia del sujeto, es decir, el sujeto que siente, percibe y recrea el significado del símbolo, ampliando el horizonte mediante la correlación de símbolos, y su forma vinculatoria, es decir, adentrarse en el lenguaje símbólico, para así, profundizar en su capacidad comunicativa y por tanto en su capacidad para existir como horizonte de posibilidad, como forma de consuelo y esperanza.

De acuerdo con las incógnitas antes expresadas, la hipótesis a explorar abordaría un acercamiento a la relación simbólica y su conformación a través de las siguientes preguntas-planteamientos: en tanto que el símbolo puede ser resignificado, ¿nos resignifica? Y por tanto, ¿funge como enlace y fuente de entendimiento entre los hombres?

Cabe recalcar que los autores en los que apoyaré este escrito pertenecen a diferentes corrientes de pensamiento. Dado que el tema es de origen filosófico, haré mención de autores que han trabajado la temática del símbolo, como son: Gilbert Durand, Mircea Eliade, Luis Garagalza y Ernst Cassirer, así como otros que, ya sea por su peso en la historia del pensamiento occidental, o por su particular visión de las cosas, aportan y enriquecen el cuerpo del texto.

Será bajo el esquema del ensayo como desarrollaré la temática en torno al símbolo y la forma será descriptiva. La labor de construir un ensayo es similar a la del gusano de seda, es un ir tanteando, como el nombre lo dice, ensayando, del francés essai, essayer. ${ }^{4}$ Se va ensayando, al tiempo que se va discurriendo, por tanto la acción de ensayar,

4 "Essayer", en Dictionnaire de la langue française, Liternaute Encyclopedie, Boulogne: http://www.linternaute.com/dictionnaire/fr/definition/essayer, 28/IV/2007. 
lleva implícita dos acciones fundamentales: explorar y experimentar. Desde la concepción latina, el ensayo es exagium, entendido como el acto de pensar. ${ }^{5}$ Y precisamente, porque el pensamiento no es concluso y da vueltas como espiral, el ensayo es la forma idónea para presentar la acción misma de razonar. La definición de Montaigne conserva actualidad:

Es el juicio un instrumento necesario en el examen de toda clase de asuntos, por eso lo ejercito en toda ocasión en estos ensayos. Si se trata de una materia que no entiendo, con mayor razón me sirvo de él, sondeando el vado desde lejos; y luego, si lo encuentro demasiado profundo para mi estatura, me detengo en la orilla. El convencimiento de no poder ir más allá es un signo del valor del juicio, y de los de mayor consideración.[...] Reflexiono sobre las cosas, no con amplitud sino con toda la profundidad de que soy capaz. ${ }^{6}$

La reflexión, como posibilidad del ensayo, es a la vez una labor de comprensión. Comprender para interpretar e interpretar para comprender. La interpretación como medio primordial y originario en la lectura de

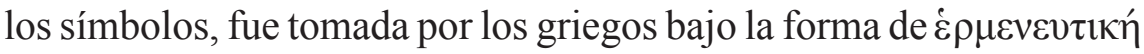
$\tau \varepsilon \dot{\chi} \chi \nu \eta$, arte de explicar, traducir o interpretar. Hermes, portador de los mensajes, traza caminos de comunicación y favorece el entendimiento humano.

A la luz de la hermenéutica griega: ¿será la interpretación una actividad, una $\tau \dot{\chi} \chi \nu \eta ?$ ¿O más bien es una cualidad del ser humano inseparable de su ser? En cualquier campo el hombre está interpretando en cada momento. No es un acto voluntario, es su modo de existencia. El hombre es $\dot{\varepsilon} \mu \eta \dot{v} \varepsilon v \sigma ı \varsigma$, por ello, hablar de hermenéutica como método sería tematizar lo intematizable.

Desde esta misma tesitura, Arturo Leyte habla del término trayecto, que no sólo define la labor hermenéutica, sino que va de la mano con la propia naturaleza del ensayo. Trayecto, tiene como origen el término

5 “Ensayo", en Diccionario Clave, 1989, Madrid, SM, p. 711.

${ }^{6}$ Michel de Montaigne, Ensayos, 2003, Madrid, Cátedra, p. 28. 
francés trajet $^{7}$ y habla de una línea descrita en el espacio por un punto móvil.

Trayecto significa que la propia obra surge y como tal. No se elige, así pues, escribir una obra, o un camino, como si eso obedeciera a una decisión metodológica, sino que se parte del reconocimiento de que aquello de que trata la filosofía, no puede concluir en ningún contenido. ${ }^{8}$

La idea de trayecto toma especial relevancia, debido a que continuamente se está haciendo, nunca es. Somos capaces de divisar el horizonte, de describirlo, pero jamás de alcanzarlo. La filosofía es parte de este misterio: es trayecto, y al tratar de asirla nos desborda. Leyte, haciendo alusión a la filosofía de Platón y la imagen de la caverna y la búsqueda de la verdad, refuerza la idea con el término tránsito. "Tránsito de lo oculto a lo desoculto, en el que lo oculto se refugia, pero no desaparece, en lo desocultado. Y este tránsito define algo más que la esencia de la verdad: define la verdad, entendida como tránsito, de la esencia". 9

A la luz del lenguaje simbólico: el trayecto, el tránsito, el ocultar y desocultar, son parte del misterioso lenguaje que da lugar a un diálogo en dos sentidos: el hombre que se acerca al símbolo para interpretarlo, y el símbolo que se actualiza en tal acción.

\section{Del símbolo y su representación}

¿Sentiríamos el escalofrío del mal si no tuviéramos la imagen de fuego? ¿Compartiríamos el sentimiento de la pasión sin esta misma imagen? ¿Podríamos hablar del conocimiento sin hablar de luz? ¿Podemos sostenernos con meras descripciones o abstracciones? ¿Por qué la humanidad ha utilizado al símbolo para expresarse?

Comencemos abordando tales cuestiones desde una pregunta que nos parece más elemental: ¿por qué podemos hablar del símbolo?

7 “Trajet”, en Dictionnaire de la langue française, Liternaute Encyclopedie, Boulogne http://www.linternaute.com/dictionnaire/fr/definition/trajet 28/IV/2007.

${ }^{8}$ Arturo Leyte, Heidegger, 2005, Madrid, Alianza, p. 10.

${ }^{9}$ Ibid., p. 238. 
¿Qué es lo que lo hace real? Nuestro punto de partida será acercarnos mediante su manifestación, es decir, el acontecimiento, para hablar de él. Habrá que considerar que acontecer viene del latín contingere ${ }^{10}$ que significa suceder. El fenómeno simbólico es un hecho en tanto acontece, sucede en el hombre, sucede en mí. Chantal Maillard lo dice de una forma original:

Nada cierto puedo decir de las cosas y sus relaciones. Indudablemente, sólo puedo hablar de mí y sólo puedo hacerlo con el lenguaje que he aprendido; las cosas y los otros son en mí. [...] Preguntar por la realidad de algo, ¿es preguntar por su continuidad por su adecuación, por su intensidad? ${ }^{11}$

¿En qué momento aparece el símbolo? ¿Cuándo se establece una relación simbólica entre el hombre y la realidad? Partamos del inicio, de las primeras manifestaciones que nos hablan de un origen. ¿Es posible hablar del nacimiento del símbolo? ¿La fuerza simbólica es independiente del hombre? Mircea Eliade comenta lo siguiente: "la naturaleza adquirió un valor simbólico en cuanto el hombre tomó conciencia del mundo como un conjunto cosmológico y se reveló el ritmo cósmico aunque se ignore este momento". ${ }^{12}$

El hombre en un afán por congraciarse con las fuerzas de la naturaleza, se vincula, conversa, se fusiona con su medio; busca crear una posición en el mundo, necesita identificarse con su medio, asirse: "Transformar el mundo pasivo de las meras impresiones en una vía de conocerlo por medio de esas expresiones espirituales." ${ }^{13}$ Estas primeras premisas dan el soporte para afirmar que el símbolo es, en tanto que hay un sujeto que lo percibe, lo crea y lo reinventa. Podrán existir elementos naturales, pero la connotación simbólica y el ejercicio de simbolizar pertenecen sólo al hombre. Hablar de "hombre simbólico" sería, en este sentido, una redundancia.

\footnotetext{
10 “Acontecer", en Diccionario Clave, 1989, Madrid, SM, p. 24.

${ }^{11}$ Chantal Maillard, Filosofia en los días críticos, 2001, Valencia, Pre-textos, p. 113-114.

${ }^{12}$ Mircea Eliade, Tratado de las religiones, México, Editorial Era, 1964, p. 393.

${ }^{13}$ Ernst Cassirer, Filosofia de las formas simbólicas, 1998, México, FCE, tomo 1, p. I: 2.1.
} 
Frágil e insuficiente, el hombre no puede sobrevivir con el puro instinto. Es a la vez una debilidad y una fortaleza, pues más allá de resolver cuestiones fisiológicas, se empeña en desarrollar formas más elaboradas de sobrevivencia como es la creación de relatos en tanto manifestación de su locuacidad. Ello es tan natural como para las aves hacer nidos y para las tortugas poner huevos; es parte de su ser.

Estas formas elaboradas de sobrevivencia son precisamente la expresión simbólica que se manifiesta en lo que Savater llama un querer decir $^{14}$ calificándolo como lo esencial de nuestro quehacer humano. El hombre no se limita a decir de forma llana y directa, busca formas indirectas, complicadas y gratuitas de compartir sentimientos. En la necesidad de leer la realidad, hace una especie de traducción; es una forma de decodificar aquello que acontece. En palabras de Fernando Bayón: "donde faltan las evidencias, la retórica crea instituciones", ${ }^{15}$ lo que explica por qué el hombre actúa de una forma re-flexionada. Animal de los rodeos, de las invenciones, de las indirecciones y los desplazamientos, el hombre necesita del símbolo para entenderse con el mundo, así se entiende mejor a sí mismo y evita, como lo indica Garagalza "la compulsión que comporta la presencia directa". ${ }^{16}$ Dicha trama descansa sobre la premisa fundamental del conocimiento que, desde su cualidad de desvelamiento y dentro del contexto simbólico, no se muestra nunca por completo, otorgándole al símbolo la posibilidad de ser descubierto.

María Zambrano habla del ser escondido: "el conocimiento que busca nace del anhelo de darse a conocer, que acompañará siempre a las formas más objetivamente logradas del conocimiento". ${ }^{17}$ Es también lo que ella denomina la palabra que se guarda, se guarda porque está contenida y por ser de una naturaleza inacabable. Se trata de un acercamiento al $\lambda$ ó o recóndito, a aquello que no se muestra por completo, ${ }^{18}$

${ }^{14}$ Fernando Savater, Las preguntas de la vida, 1999, Barcelona, Ariel, p. 108.

${ }^{15}$ Palabras de Fernando Bayón durante el curso Metáforas de una secularización, Verano de 2005, México, UIA.

${ }^{16}$ Luis Garagalza, La interpretación de los símbolos. Hermenéutica y lenguaje en la filosofia actual, 1990, Barcelona, Anthropos, presentación de Ortiz Osés, p. 49.

${ }^{17}$ María Zambrano, Claros del bosque, 1977, Barcelona, Seix Barral, p. 28.

${ }^{18}$ Ibid., p. 89. 
ANA BARBERENA

aquello que en ocasiones se muestra parcialmente, que en otras se esconde y en otras se insinua por medio del mito y el arte.

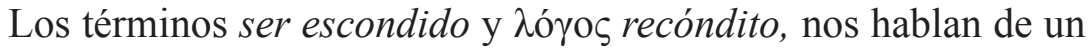
conocer que no florece a simple vista, arcano que requiere de mayor detenimiento y en todo caso de mayor imaginación. No hablamos de un conocimiento donde el concepto es objetivo, presentacional, distinguido por su univocidad, adecuación, posibilidad de comprobación, sistematización y homogeneidad. Hablamos más bien de un conocimiento donde habría que reconsiderar la $\varphi \alpha v \tau \alpha \sigma \alpha^{19}{ }^{19}$ en términos griegos, como la gran creadora, mediadora y portadora del misterio. La $\varphi \alpha \nu \tau \alpha \sigma i \alpha$, toma la forma de imaginatio en latín. Fantasía e imaginación como sinónimos nos refieren a "la posibilidad de evocar o producir imágenes independientemente de la presencia del objeto al cual se refieren". ${ }^{20}$ Imaginar nos centra especialmente en ser posibilidad de conocimiento. Imaginar es conocer y conocer es experimentar. Hobbes apunta hacia esta cualidad de experiencia propia de la imaginación donde le atribuye "la memoria, la experiencia y, por su mediación también el entendimiento y el juicio". ${ }^{21}$ Imaginando conocemos.

Gilbert Durand habla de devolver a la imaginación la dignidad gnoseológica y ontológica de la que había sido privada por la doctrina clásica occidental22 y afirma que "no hay ruptura entre lo racional y lo imaginario; el racionalismo no es más que una estructura polarizante particular, entre otras muchas, del campo de las imágenes". ${ }^{23}$

Imaginando, experimentando, conociendo; formas naturales en el hombre que gestan el impulso por simbolizar y lograr así lo que incansablemente persigue: vincularse, sentise en el mundo: estar-en-el-mundo. El movimiento es de ida y vuelta: nos acercamos a un entorno, lo sentimos, lo experimentamos para posteriormente tomar distancia, deslindarnos y distinguirnos de lo otro a través del quehacer simbólico. Son por ello tarea vital: la religión, el mito y la creación artística; son nuestra expresión y son formas que nos relacionan con el mundo.

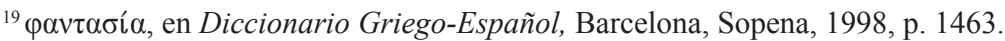

${ }^{20}$ Nicola Abbagnano, “Imaginación”, en Diccionario de Filosofia, 1998, México, FCE, p. 652.

${ }^{21}$ Thomas Hobbes, Leviatán, 2003, Madrid, Editorial Losada, I, 2.

${ }^{22}$ Luis Garagalza, La interpretación de los símbolos, 1990, Bilbao, Deusto, p. 56.

${ }^{23}$ Gilbert Durand, La imaginación simbólica, 2000, Bs. As., Amorrortu, p. 88.
} 
Los mitos de la creación se encuentran articulados mediante símbolos; las características de ciertos animales, de flores y hasta de objetos, le han servido al hombre para elaborar el imaginario simbólico. Pensemos simplemente en las cualidades de la serpiente: a medida que se desplaza, sorprende con su movimiento zigzagueante que denota una cercanía con la tierra; por otro lado, la cualidad de mudar de piel introduce la posibilidad de renacer y conferir vida.

Esto nos lleva a pensar que el símbolo sobrepasa el lenguaje pues habla más allá de éste, habla de aquello que connota, no sólo de aquello que denota. El término griego $\sigma 0 ́ \mu \beta 0 \lambda$ ov proviene del verbo $\sigma u \mu \beta \alpha ́ \lambda \lambda \omega$ que significa arrojar junto, poner conjuntamente, reunir, aproximar. ${ }^{24}$ Lo mismo ocurre con el término hebreo mashal o el alemán Sinbild que implica la unión de dos mitades. ${ }^{25}$ Esta aproximación de la que habla la definición de símbolo tiene que ver justamente con la unión de significante y significado.

El símbolo no tiene como función economizar, no sólo muestra un elemento que hace referencia a otro, va más allá de la mera sustitución. El símbolo es, en primer lugar y de por sí una representación y, como tal, fuente de ideas e imaginario. Luis Garagalza lo define como "conocimiento indirecto que hace posible la representación en una conciencia de una realidad ausente". ${ }^{26}$ Por su parte, Durand describe sus cualidades de la siguiente forma:

En primer lugar, el aspecto concreto (sensible, imaginado, figurado, etc.) del significante, en segundo lugar su carácter optimal: es el mejor para evocar (hacer, conocer, sugerir, epifanizar, etc.) el significado. Por ultimo dicho significado es a su vez algo imposible de percibir (ver imaginar, comprender, figurar, etc.) directamente. ${ }^{27}$

${ }^{24} \sigma u ́ \mu \beta 0 \lambda o v, \sigma u \mu \beta \alpha ́ \lambda \lambda \omega$, en Diccionario Griego-Español, 1998, Barcelona, Sopena, p. 1292.

${ }^{25}$ Gilbert Durand citando a R. Alleau: "De la nature des symboles", en La imaginación simbólica, 2000, Bs. As., Amorrortu, p. 16.

${ }^{26}$ Luis Garagalza, La interpretación de los símbolos, 1990, Bilbao, Anthropos, p. 49.

${ }^{27}$ Luis Garagalza, citando a Gilbert Durand: "Figures mythiques et visages de l'oeuvre", en La interpretación de los símbolos, 1990, Bilbao, Anthropos, p. 50, p. 18. 
El símbolo tiene cualidades entre las que resaltan su constante movilidad, su condición de resonancia y su enorme poder de expresión, pues no se deslinda del lenguaje; simbolizamos porque somos capaces de apropiarnos del lenguaje. En palabras de Ernst Cassirer "somos animales simbólicos". 28

El símbolo, se nos revela como móvil y cambiante, lo que impide examinarlo de forma puntual y delimitada. La re-presentación simbólica nunca puede confirmarse mediante la presentación pura y simple de lo que significa. La parte visible del símbolo, es decir, el significante, estará enmarcado por la claridad y especificidad; sin embargo el significado puede tener enormes variaciones. El símbolo, solo, vale por sí mismo.

\section{Interpretación y epifanía del símbolo}

El símbolo no está hecho para ceñirlo a un sistema cerrado, el símbolo acontece, pero evade; las características del símbolo, lejos de seguir un orden, se comportan como lo hace el propio símbolo: en espiral o a la manera de un rizoma. Son movimientos simultáneos: percibimos al tiempo que conocemos e interpretamos.

Existen vínculos o conexiones entre los símbolos que permiten crear cadenas que se entretejen y que se amplifican hacia el lenguaje simbólico que deviene por sí mismo.

En el curso de las edades, gracias a la evolución de las culturas y los espíritus, él (el símbolo) se traduce en un lenguaje nuevo, desencadena resonancias imprevistas, devela sentidos desapercibidos. Pero mantiene su orientación primordial, la fidelidad a la intuición original, una coherencia en sus interpretaciones sucesivas. ${ }^{29}$

En esta acción de tejer, el símbolo comparte ciertas características con el juego, que desde la concepción de Huizinga en su obra Homo

${ }^{28}$ Ernst Cassirer, Filosofía de las formas simbólicas, 1998, México, FCE, Tomo 1, p. I: 2.1.

${ }^{29}$ Jean Chevalier y Alain Gheerbrandt, Diccionario de los símbolos, 1991, Barcelona, Herder, p. 36. 
ludens,${ }^{30}$ lleva intrínsecamente las cualidades de representatividad y movilidad. Re-presentar ${ }^{31}$ como la acción de volver a presentar, como una forma de imitar. El juego en tanto representación lleva implícita una figuración ${ }^{32}$ pues insinúa "esa otra cosa" y eso mismo ocurre con el símbolo. La movilidad se muestra por medio de nuevos significados que toman un cariz distinto dependiendo de la cultura, el grupo o la persona que se apropia de ellos. Es decir, al descifrar un solo símbolo, éste se expande y contagia nuevas visiones; el concatenarse símbolo con símbolo se relaciona con su condición de elemento del devenir, que le impide ser aprehendido en su carácter cambiante; refleja su polivalencia y tiene la cualidad de conformar redes porque se articula hacia otros símbolos; entre más articulaciones, mayor extensión de la urdimbre.

Tal cualidad expansiva es fundamental para la comprensión del lenguaje simbólico. Lo que habría que recalcar dentro de ese movimiento de repetición y vinculación es que el símbolo acierta en su andar en tanto a que "atina". Gilbert Durand le llama "redundancia perfeccionante"33 que se sostiene por una coherencia interna, lo que los especialistas del símbolo llaman un isotopismo, de iso (igual) y de tópos (lugar). ${ }^{34}$ Bayón lo describe de la siguiente manera:

Esa errancia de sentido que contempláramos antes como la movilidad que le era específica a los procesos simbólicos parece que, después de todo, no yerra tanto; que los fragmentos del sentido se arraciman en relatos que siempre con-vienen a los mismos, que recurrentemente dejan de instituir e investir a algunos, a muchos, a la mayoría. ${ }^{35}$

Múltiplicidad de significados, transformación constante, el símbolo cuenta con desbordante riqueza que Garagalza califica como aquello que está revestido con un excedente de significación ${ }^{36}$ o lo que Ernst Cassirer

\footnotetext{
${ }^{30}$ Johan Huizinga, Homo ludens, 1957, Buenos Aires, Emecé.

31 "Representar", en Diccionario Clave, Madrid, SM, p. 1586.

${ }^{32}$ Johan Huizinga, op. cit., pp. 23, 28.

${ }^{33}$ Gilbert Durand, La imaginación simbólica, 2000, Buenos Aires, Amorrotu Editores, p. 17.

34 "Isotopismo", en Diccionario Clave, Madrid, SM, p. 1044.

${ }^{35}$ Fernando Bayón, "símbolo", en Claves de Hermenéutica, 2000, Bilbao, Deusto, p. 519.

${ }^{36}$ Luis Garagalza, La interpretación..., op. cit., p. 50.
} 
ANA BARBERENA

ha llamado preñez de significado, ${ }^{37}$ o lo que Fernando Bayón denomina hemorragias de sentido. ${ }^{38}$

Si el símbolo atraviesa, como expresan estos autores, por un proceso de significación, a la vez que tiene como trasfondo "hemorragias de sentido", es porque implica en su manifestarse al hombre en su capacidad interpretativa es decir, en cuanto $\dot{\varepsilon} \rho \mu \varepsilon v \varepsilon i \alpha^{39}$ o interpretación, voz griega que significa primeramente expresión del pensamiento; de ahí explicación y, sobre todo, interpretación del mismo, en tanto que orienta en el mundo dando cohesión al estar, al arraigarnos otorga identidad, gracias a ella imaginamos que está el mundo dotado de un cierto sentido. Desde esta perspectiva y de cara al lenguaje simbólico, entenderemos la hermenéutica como el acto de estar abierto como ese ánimo de recuperar los sentidos, afinar nuestro gusto, vista, tacto y oídos. Siguiendo a Gadamer:

Y así, es la identidad hermenéutica la que funda la unidad de la obra. En tanto que ser que comprende, tengo que identificar. Pues ahí había algo que he juzgado, que "he comprendido". Yo identifico algo como lo que ha sido o como lo que es, y esa identidad constituye el sentido de la obra ${ }^{40}$

La interpretación está íntimamente ligada al $\lambda o ́ \gamma o \varsigma$ porque bajo este $\lambda$ ó $o \varsigma$ el hombre nombra, "lee la realidad", simboliza a la vez que interpreta, comprende y se autocomprende. Por ello es un término visto como palabra y mediación divina, es nuestra herramienta de orden, nuestro vínculo.

El "círculo hermenéutico"41 que Gadamer describe en su obra Verdad y Método (1977), será el marco de aproximación en torno al símbolo, en tanto que el intérprete que se enfrenta al símbolo no es tabu-

${ }^{37}$ Ernst Cassirer, Filosofia de las formas simbólicas, op. cit., p. I: 2.1.

${ }^{38}$ Fernando Bayón, op. cit., p. 516.

${ }^{39} \dot{\varepsilon} \rho \mu \varepsilon v \varepsilon i ́ \alpha$, en Diccionario Griego-Español, 1998, Barcelona, Sopena, p. 568.

${ }^{40}$ Hans-Georg Gadamer, La actualidad de lo bello, 1991, Barcelona, Paidós, trad. de Antonio Gómez Ramos, introducción de Rafael Argullol, p. 71-72.

${ }^{41}$ Hans-Georg Gadamer, Verdad y método, 1977, Salamanca, Ediciones Sígueme, p. 333. 
la rasa, no puede desconocer su horizonte móvil; echa mano de aquello que le precede, que sería lo que Gadamer llama prejuicios o Vorurteile. ${ }^{42}$ Lejos de darles una connotación negativa, Gadamer les da la categoría de ideas o conjeturas: "los prejuicios de un individuo son, mucho más que sus juicios, la realidad histórica de su ser". ${ }^{43}$ A pesar de que el intérprete no tiene más remedio que leer desde su perspectiva y su precomprensión, ello no debe determinar la lectura del símbolo de forma unívoca, antes bien hay que dejarle hablar para que transmita aquello que le es propio. El hecho de conducirnos mediante prejuicios debe volverse una medida consciente de acercamiento, a fin de no afectar la interpretación con juicios precipitados o arbitrarios y de lograr mirar con claridad aquello que se nos revela a la luz de nuestras expectativas.

En resumen: en el acto de interpretar, el intérprete reelabora su trasfondo cultural, lo pone en juego frente al nuevo símbolo. Es un movimiento de ida y de vuelta, mejor dicho, es un círculo que Gadamer llama círculo hermenéutico. ${ }^{44}$ Se comprende bajo este término un ejercicio interpretativo inacabable. Un símbolo aparece e invita a ser descubierto, el intérprete se acerca, lo estudia, lo confronta con su propia experiencia y extrae su significado. Pero al momento en que se suman otros significados, el primer símbolo se reelabora, se actualiza y cambia. Cada interpretación se lleva a cabo a la luz de lo que se sabe y de lo que el intérprete conoce, por lo tanto, en el transcurso de la historia humana el contexto varía y el símbolo permanece como un organismo vivo de posibilidades infinitas.

Quizá una de las imágenes que mejor describe este círculo hermenéutico hacia el símbolo es la que Gadamer señala en su obra La actualidad de lo bello, ${ }^{45}$ donde hace alusión a la tessera hospitalis definiéndola como "tablilla de recuerdo" 46 que el anfitrión le regalaba a su huésped. La pieza se rompía en dos quedando cada uno con una mitad, tal acto

${ }^{42}$ Ibid., p. 337.

${ }^{43}$ Ibid., p. 344.

${ }^{44}$ Ibid., p. 333.

${ }^{45}$ Hans-Georg Gadamer, La actualidad de lo bello, op. cit., p. 72.

${ }^{46}$ Ibid., p. 84. 
representaba un pacto entre los involucrados. Ésta fue una costumbre muy arraigada en los pueblos indoeuropeos occidentales: acuerdo de amistad y vinculación por la cual los implicados se ofrecían mutua protección.

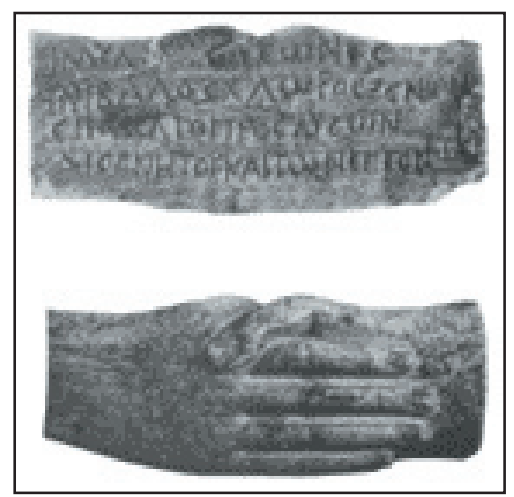

Tessera hospitalis

La magia de la tessera radicaba en sus alcances y en su capacidad para resignificarse puesto que mantenía un pacto más allá de las personas que intervenían en la partición, el acuerdo se extendía hacia los descendientes que podían actualizarlo y revitalizar el poder de la pieza al encontrar esa otra mitad y re-conocerse en un contexto cada vez distinto, con un universo de acogida singular y específico. Entendemos reconocer, recognoscere como el acto de volver a conocer, enfrentarse a aquello que algún día se habitó, coincidiendo con el propio significado del $\sigma u ́ \mu \beta o \lambda o v$, desde la noción de contrato, convenio, encuentro. En palabras de Gadamer, "es justamente la indeterminación del remitir la que nos colma con la conciencia de la significatividad, del significado característico de lo que tenemos ante nuestros ojos". ${ }^{47}$

Por otro lado, la tessera hospitalis resalta la condición de recepción que involucra el quehacer simbólico. Centrarse en la recepción y en la facultad para significar nos lleva a la posibilidad de acercarnos a aquello

${ }^{47}$ Ibid., p. 83. 
que se nos revela. El símbolo es fuente de posibilidades, pues nunca es adquirido por completo y permite a cada persona acercarse con su propio imaginario revelándole algo distinto y coimplicándose con el otro.

Si por un lado es posible acercarnos a la lectura de un símbolo gracias a la hermenéutica, por el otro, no podremos aprehenderlo del todo. Es en este punto donde el símbolo muestra su perfil más paradójico, pues

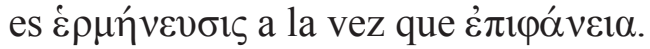

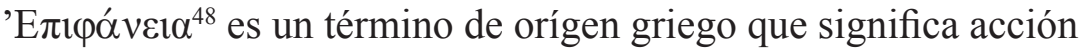
de mostrarse, aparición. Ello nos habla de que a pesar de que podemos conocer parte de aquello que se nos revela en un símbolo, siempre queda un resquicio, una incógnita, un misterio. La labor interpretativa será siempre insuficiente debido a esta cualidad epifánica. Gadamer la define como "lo inefable, aquello para lo cual no existe concepto verbal, se manifiesta, se encarna en y por la imagen, se expresa en una figura". ${ }^{49}$ La epifanía que pervive en el significante hace de aquello que muestra la concretud, una forma abstracta e indefinida. Inatrapable.

\title{
Hacia la compasión mediante el lenguaje simbólico
}

\author{
Digo "tú" y estoy diciendo "yo". Digo "tú" de la \\ misma manera que digo "mundo". Nunca salgo del \\ círculo. Me atrapo con el lazo una y otra vez. "Tú" es \\ el nudo corredizo con el que aprieto mi garganta \\ para medir su resistencia. \\ Chantal Maillard
}

La habilidad del ser humano para identificarse y vincularse con otros es tan añeja como la vida misma. Una investigación interesante sobre los descubrimientos de Atapuerca dieron origen a la obra La especie elegida ${ }^{50}$ donde los autores establecen la hipótesis de que la extinción de los neardenthales no está relacionada con ninguna inferioridad física,

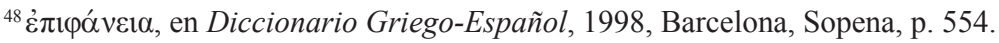

${ }^{49}$ Hans-Georg Gadamer, La actualidad de lo bello, op. cit., p. 50.

${ }^{50}$ Juan Luis Arsuaga e Ignacio Martínez, La especie elegida, 2005, Madrid, Ediciones Temas de hoy. 
cerebral o de adaptación al medio, sino con su incapacidad, respecto al antecesor, para reconocer a los miembros de su especie. Ellos eran capaces de distinguir a los miembros de su grupo, pero no a los de otros grupos. La habilidad para re-conocerse entre pares es uno de los rasgos más definitorios del hombre, a la vez que el mayor de los escollos.

Al mirarse en el otro, el hombre se reconoce y más allá de ello, mediante la convivencia, se inserta en relaciones intersubjetivas que devienen comunidad. En este "todo" tanto la lectura del símbolo como sus resonancias involucran a los integrantes del grupo en un quehacer común. "Me transformo en lo que miro porque reflejo lo que miro", ${ }^{51}$ lo cual quiere decir que me transformo con el otro, me significo con el otro. Esto nos remite a una tradición, pues no hay símbolos personales o exclusivos, como señala Gadamer "es de la tarea hermenéutica explicar este milagro de la comprensión, que no es una comunión misteriosa de las almas sino participación en un sentido comunitario".52

Por lo anteriormente expuesto podemos afirmar que los hombres se entrelazan entre ellos, y con el mundo por medio de los símbolos, pues éstos tienen una cualidad co-implicativa. En esta convergencia de gestos, hay una comunión de dimensiones profundas hecha con base en una construcción paritaria del lenguaje simbólico, cuyo efecto catártico desencadena reverberaciones no sólo de cara al hombre mismo, sino como expansión e inclusión de la humanidad.

Del símbolo al lenguaje simbólico, la acción desarrollada en este movimiento remite una vez más a la definición del $\sigma u ́ \mu \beta o \lambda o v$ como acción de re-unir, re-mitir, re-ligar, donde subyace el impulso de vinculación. Ejemplo de ello es la tragedia griega, que manifiesta la vulnerabilidad del hombre que se reconoce al simpatizar con determinados personajes o situaciones, pues ante una experiencia reveladora llega a experimentar una serie de contenidos de carácter vital, es espectador de innumerables situaciones que es incapaz de imaginar, pero que vive directamente porque se identifica con el personaje por medio de la simpa-

${ }^{51}$ Chantal Maillard, Filosofía en los dias criticos, op. cit., p. 107.

${ }^{52}$ Hans-Georg Gadamer, Verdad y método, op. cit., p. 362. 
tía-empatía. Por medio de la tragedia rememora la muerte, el amor, el dolor, la soledad entre tantas otras emociones.

Otro ejemplo donde se observan estas cualidades del lenguaje simbólico es en el arte, que es capaz de despertar y hacer reconocer en el sujeto sentimientos diversos. De ahí que la ká $\ \alpha \rho$ ıৎ cobre toda su fuerza, porque ante la mirada, ante el deseo de desentrañar un significado, hay un interés desinteresado que genera una identificación, una coincidencia del yo en el otro.

El lenguaje simbólico conlleva un ejercicio vital de alteridad y de comprensión del otro, porque interpretarlo es intentar comprenderlo desde su diferencia, es decir, que la consecuencia que sobreviene de forma inmediata cuando interpreto una expresión simbólica es encontrar que el fundamento de la semejanza es la diferencia. El vínculo que se desarrolla en el diapasón de diferencia y semejanza es un denominador común que sustenta una igualdad en la disparidad. En la disimilitud tocamos la vulnerabilidad, la conciencia de finitud, que posibilita la compasión, es decir, a través del símbolo re-conocemos al otro en su labilidad, y es en esta condición de desnudez donde se gesta la compasión. ¿El símbolo es compasivo?

El símbolo es compasivo en tanto que provoca el giro o movimiento pendular de semejanza a diferencia y viceversa, que lleva a cabo gracias a la imaginación. Somos compasivos en la medida en que imaginamos, pues la imaginación funge primeramente como mediadora y segundo, como co-creadora, ya que nos permite completar, al modo de la tessera, aquello que yace oculto. La imaginación es, por otro lado, portadora de la memoria. Desde la visión de Hume, la imaginación "acompaña a la memoria misma como acompaña a la sensibilidad"; 53 por ello, la imaginación en tanto que posibilita el recordar, remite al experienciar o experimentar diversas emociones, así podemos ser arrastrados por el dolor o el goce, a través del simple mirar.

Aristóteles ahonda en el tema de la tragedia y la describe como el espacio para hacer florecer multiples sentimientos, entre otros, la compa-

${ }^{53}$ Nicola Abbagnano, "Imaginación”, en Diccionario de Filosofia, 1998, México, FCE, p. 652 . 
sión. "Es necesario que los que refuerzan el efecto con sus actitudes exteriores, con sus voces, con su vestido y, en general con lo que es teatral, despierten más la compasión; ya que hacen que el mal parezca más inmediato al ponerlo ante los ojos, o como inminente o como recién sucedido". ${ }^{54}$ Desde la visión aristotélica, la cercanía es un elemento fundamental, pues el dolor se comparte desde la proximidad, desde la mirada, no desde lo ajeno o desde la distancia. Sentimos la compasión desde la semejanza, en tanto que aquello que le sucede al otro puede ocurrirnos también, es decir, en la medida en que somos capaces de imaginar, somos capaces de con-mover-nos a través de com-padecer-nos.

Entendemos la palabra compasión siguiendo su raíz latína compassio derivada de compatitor que significa "padecer con otro, conjuntamente"; 55 passio, de pasión bajo la forma de "perturbación o ánimo muy intenso", pero también como "padecimiento o sufrimiento". ${ }^{56}$ El término conserva el significado de la $\sigma 0 \mu \pi \alpha ́ \alpha \theta \varepsilon \_$griega como "participación en el sentido del otro, comunidad de sentimientos o impresiones; reacción o correspondencia entre ciertas cosas". ${ }^{57}$

Se nos revela así, la condición más original de la compassio, que es ser afectado, es decir, mueve a ponerse en el lugar del otro en tanto que se reconoce como semejante. La compasión es acto, y en tanto acto humano porta consigo el sentido de dignidad al asumirse la finitud. El otro soy yo, y como señala Kundera en su obra La insoportable levedad del ser:

El secreto poder de su etimología ilumina la palabra con otra luz y le da un significado más amplio: tener compasión significa saber vivir con otro su desgracia, pero también sentir con él cualquier otro tipo de sentimiento: alegría, angustia, felicidad, dolor. Esta compasión [...] significa también la máxima capacidad de imaginación sensible, el arte de la telepa-

${ }^{54}$ Arist., Po., 1386 b.

${ }^{55}$ Compatitor, en Diccionario latino-español, 1954, Barcelona, Editorial Ramón Sopena S.A., p. 262.

56 "Pasión", en Diccionario Clave, 1989, Madrid, SM, p. 1369.

${ }^{57}$ Compassio, en Diccionario latino-español, op. cit., p. 262. 
tía sensible; es en la jerarquía de los sentimientos el sentimiento más elevado. ${ }^{58}$

Recapitulando: el camino hacia la compasión se desarrolla en la aceptación profunda del otro, donde se exploran tres movimientos, dos ya mencionados: diferencia-semejanza que deviene en com-padecer /auto-padecer y un tercero que consiste en trasladarnos fuera de nosotros para regresar a nosotros mismos, punto inicial de esta ejecución, que describe Aristóteles cuando ahonda en la concepción de la compasión en su obra La Retórica, la cual define como "cierta tristeza por un mal que aparece grave o penoso en quien no es merecedor de padecerlo; el cual mal podría esperar padecerlo uno mismo o alguno de los allegados de uno". ${ }^{59}$ La compasión será el asidero a la vez que el horizonte, o mejor dicho y más allá de una linealidad, será el componente esencial de una espiral, pues más allá de un uso en ocasiones degradado de conmiseración o lástima, brilla como forma encuentro.

¿Es posible encontrarnos en este mundo convulso y complejo? ¿Somos compasivos? Diariamente observamos el horror a través de miles de imágenes, sin caer en cuenta que no somos capaces de procesarlas, pues contaminan hasta paralizar la imaginación, sufrimos la desconexión entre lo que vemos y lo que sentimos. Ante esto, se nos presenta la trillada consigna general dirigida hacia la solidaridad, hacia la tolerancia. Pareciera que son estos los últimos reductos de relación y convivencia entre los hombres.

¿Cómo sentir nada más que solidaridad, si el hombre no es cercano al otro, si no lo entiende? Para acercarse necesita prestar atención; echar mano de la lectura y la observación cuidadosa. La compasión se gesta en el trato personal, no en las grandes movilizaciones y convocatorias masivas, por ello es esencialmente encuentro, trato. Aristóteles en La Retórica, como fue mencionado, enuncia que para ser compasivos es necesario ser cercanos. La compasión ha de ser hallada en actos aparentemente simples como escuchar, compartir y recordar. Hay

${ }^{58}$ Milan Kundera, La insoportable levedad del ser, 1985, México, Tusquets, p. 28.

${ }^{59}$ Arist., Rh., 1382 a 20. 
tiempos en los que las personas sólo se consuelan en la voz de alguien que ha experimentado su mismo pesar, cara a cara, fundan un diálogo; se escuchan y son escuchados lejos del parloteo.

La compasión no siempre muestra su cara amable, normalmente se finca en un profundo dolor. El siglo pasado y el presente son muestra de esta carencia: las guerras, los genocidios, las hambrunas, exponen el olvido del otro. La compasión, lejos de ser un privilegio como lo decía el Marqués de Sade, en la obra Persecución y asesinato de Jean Paul

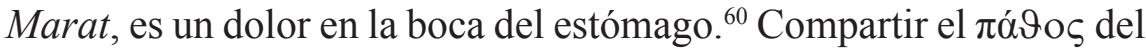
otro, sea quien sea, es afirmar que la agonía no está exenta de la vida propia.

En este mismo sentido y como un atisbo de vida, la compasión pervive como elemento de liberación y reconciliación personal, como búsqueda a la par que encuentro. A través suyo, el trato con el otro se carga de sentido. En el fondo, lo que subyace, es un profundo interés por encontrar la unidad o centro, que en tanto móvil, se desplaza simultáneamente con el símbolo que busca ser completado.

La compasión es el punto de partida y de llegada, se instaura desde el estar siendo, trayecto donde habitar en múltiples ocasiones roza lo desconocido, aquello que nos trasciende, lo incomprensible para comprendernos un poco.

Ante el inexorable destierro de Dios, los hombres no tenemos más remedio que avocarnos a nosotros mismos. La falta de estructuras, leyes o normas obligan primeramente a confrontar el desencanto y recrear significados. El hombre será lo que haga de sí mismo y el lenguaje simbólico es su universo de posibilidad; pensar desde la alteridad; concebir al símbolo como consuelo, como compasión que invita a descifrar e intentar comprender. ¿Habrá algo verdaderamente ajeno entre seres humanos? La propuesta es valernos de nuestra imaginación para interpretar, comprender, con-mocionarse, com-padecer por medio del gozo.

Interés y curiosidad por desvelar símbolos, por desentrañar misterios. La apuesta es arriesgarse a escuchar atentamente la voz del símbolo,

${ }^{60}$ José Ramón Enríquez, en "Recuperar la compasión”, citando una frase de la obra teatral: Persecución y asesinato de Jean Paul Marat de Peter Weiss, en Reforma 2004. 
serenarse y dejarlo mover, dejarlo hablar, fluir con él. En un contexto sociohistórico de violencia, es urgente dar cabida al símbolo compasivo y rozar el lenguaje de la mirada, de la posibilidad, como mencionó Amos Oz en su discurso, de "imaginar al otro", ${ }^{11}$ ejercicio estético que coimplica una eticidad, una forma de estar, porque "vivir humanamente significa vivir con sentido, es decir, vivir simbólicamente". ${ }^{62}$ La propuesta es establecer ocasiones de reconocimiento, de igualdad y de lectura, por medio del símbolo que pone en práctica aquello que mayor concede: nuestra vocación de ser con los otros.

${ }^{61} \mathrm{Amos} \mathrm{Oz}$, "El mal tiene un olor inconfundible", en op. cit., p. 24.

${ }^{62}$ José María Mardones, "La racionalidad simbólica", en Symbolon. Ensayos sobre cultura, religión y arte, 2005, México, UNAM, Instituto de Investigaciones Filológicas, p. 71. 
CITAM Derechos Reservados.

La reproducción total o parcial de este artículo se podrá hacer si el ITAM otorga la autorización previamente por escrito. 